\title{
Особенности анатомического строения семенной кожуры Viola hirta L. и Viola selkirkii Pursh (Violaceae)
}

\section{Features of the anatomical structure of the seed coat of Viola hirta L. and Viola selkirkii Pursh (Violaceae)}

\author{
Елисафенко Т. В. ${ }^{1}$, Полубоярова Т. В. ${ }^{2}$ \\ Elisafenko T. V. ${ }^{1}$, Poluboyarova T. V. ${ }^{2}$ \\ ${ }^{1}$ Центральный сибирский ботанический сад СО РАН, г. Новосибирск, Россия.E-mail: tveli@ngs.ru \\ ${ }^{2}$ ФИЦ Институт ичитологии и генетики СО РАН, г. Новосибирск, Россия. E-mail: tanita11@mail.ru \\ ${ }^{1}$ Central Siberian Botanical Garden SB RAS, Novosibirsk, Russia \\ ${ }^{2}$ Federal Research Center Institute of Cytology and Genetics of the Siberian Branch of the RAS, Novosibirsk, Russia
}

\begin{abstract}
Peфepam. Представлена структура семенной кожуры (спермодермы) зрелых семян Viola hirta L. из секции Viola и Viola selkirkii Pursh. из секции Violidum. Дано описание слоев тесты и тегмена. Предложенная обобщенная схема строения семенной кожуры рода Viola может использоваться для анализа ее модификации у видов рода.
\end{abstract}

Ключевые слова. Анатомическое строение, семенная кожура, Viola hirta, Viola selkirkii.

Summary. The structure of the seed coat of mature seeds of Viola hirta L. from the Viola section and Viola selkirkii Pursh from the Violidum section is presented. A description of the testa and tegmen layers is given. The proposed generalized scheme of the structure of the seed coat of the genus Viola L. can be used to analyze its modification in species of genus.

Key words. Anatomical structure, seed coat, Viola hirta, Viola selkirkii.

Виды рода Viola L. (более 450 видов) составляют половину семейства Violaceae. В Сибири произрастает 46 видов, многие из которых эндемики. Морфологические особенности сибирских видов недостаточно изучены, особенно это касается строения семян. Структуру спермодермы как ультраскульптура, так и анатомическое строение используют обычно для решения таксономических вопросов (Вылцан 1990; 1992; Никитин, 2001; Gil-ad, 2008). В настоящее время в связи с проблемами в уточнении таксономического статуса некоторых видов нами начато комплексное исследование морфологии семян, а также анатомии и ультраскульптуры спермодермы российских видов рода Viola (Елисафенко, 2018б). Многие виды данного рода являются диморфными - имеют два типа цветка (хазмогамные и клейстогамные). Семена образуются в основном от клейстогамных цветков при автогамии. Поэтому многие морфологические признаки характеризуются незначительной изменчивостью. Виды рода Viola - диплохоры (мирмекохоры и автомеханохоры), мирмекохории способствует крупный присемянник (ариллоид) (рис. 1). Данные по спермодерме видов рода представлены в литературе незначительно. Цель данной работы - выявить основные черты в структуре спермодермы Viola hirta L. и Viola selkirkii Pursh.

Объектом исследования явились виды из подрода Nomimium: Viola hirta L. из секции Viola и Viola selkirkii Pursh. из секции Violidum. Оба вида - многолетние короткокорневищные растения с широким ареалом: V. hirta имеет евразийский (европейско-сибирский) ареал, V. selkirkii - евразийско-североамериканский. Первый вид является ксеромезофитом и мезоэутрофом, относится к лесолуговой фитоценотической группе. Обитает в лесах, на лугах, оврагах, залежах. Второй вид обладает экологической пластичностью, его относят к эумезофитам, ксеромезофитам, гемигидрофитам, мезоэутрофам, мезоолиготрофам, мезоэутрофам, преимущественно мезофит, лесной фитоценотической группы. Обитает в тенистых хвойных и смешанных лесах, заболоченных местах, оврагах. 

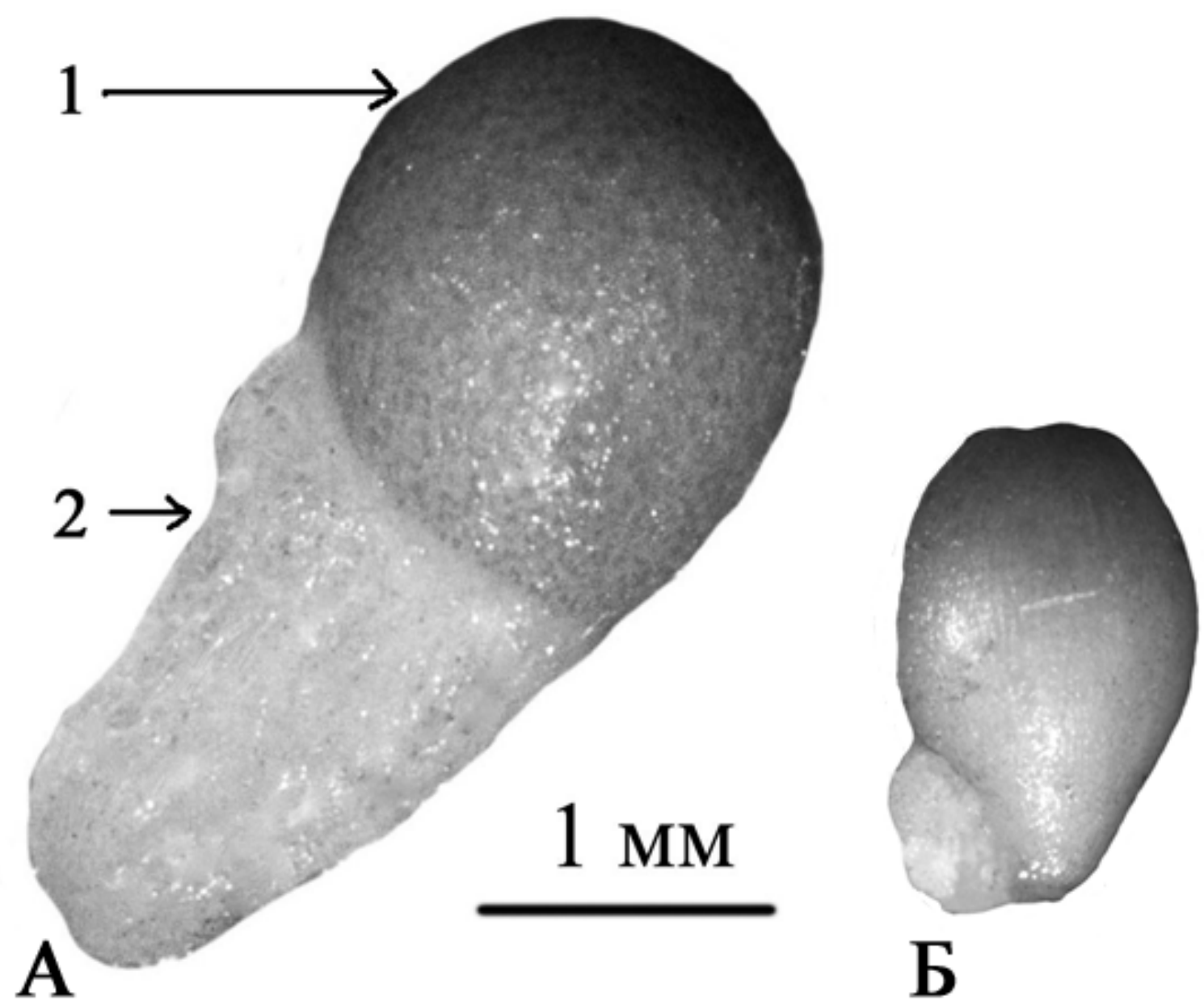

Рис. 1. Общий вид семени Viola hirta (А) и V. selkirkii (Б). 1 - семенной шов, 2 - ариллоид.

Исследование проводилось на семенах, собранных с интродукционных популяций коллекции «Violaceae», культивируемых длительное время в Центральном сибирском ботаническом саду (г. Новосибирск) (ЦСБС СО РАН). Семена собраны в 2016 г., исследования проводились в 2018-2019 гг. Семена предварительно замачивали в дистиллированной воде до 12 ч. Затем готовили временные препараты толщиной 40мкм на санном микротоме MC-2 с термоохлаждающим столиком TOC-II. Изучали неокрашенные срезы и обработанные красителями. Окраску проводили двумя способами: первый - окрашивали толуидином $(0,05 \%)$, второй - использовали комплексную окраску гематоксилином по Эрлиху и алциановым синим (Паушева, 1988). Анализ препаратов проводили с помощью светового микроскопа Axio Lab. A1 (Carl Zeiss) с цветной цифровой камерой высокого разрешения Axiocam MRc 5 с программой AxioVision 4.8 для получения, обработки и анализа изображений в Центре коллективного пользования ЦСБС СО РАН. Для обработки полученных результатов использовали метод вариационной статистики при 20-45-кратной повторности. Определяли $\mathrm{M}$ - среднюю арифметическую, $\pm \mathrm{m}$ - ее ошибку, V - коэффициент вариации (\%).

Семена $V$. hirta крупные орехового цвета. В условиях интродукции масса 1000 семян достигает 3 г. Семена с крупным эндоспермом и зародышем. Спермодерма многослойная выделяются теста и тегмен (рис. 2). В формировании ариллоида принимают участие все слои тесты, причем основная масса ариллоида образуется за счет разрастания клеток экзотесты (рис. 3). Теста составляет 43,84 $\pm 3,06 \mu \mathrm{m}$ $(\mathrm{V}=34,16$ \%). Верхний слой экзотесты представлен кутикулой, которая частично отделяется от следующего слоя. Второй слой состоит из квадратных клеток (в поперечном разрезе). Экзотеста достаточно легко отсоединяется от нижележащего слоя. Мезотеста представлена плотно прилегающими округлыми клетками в 3-4 ряда, в них содержатся пигменты. Мезотеста составляет половину тесты $-22,67 \pm$ $2,01 \mu \mathrm{m}(\mathrm{V}=47,00 \%)$. 

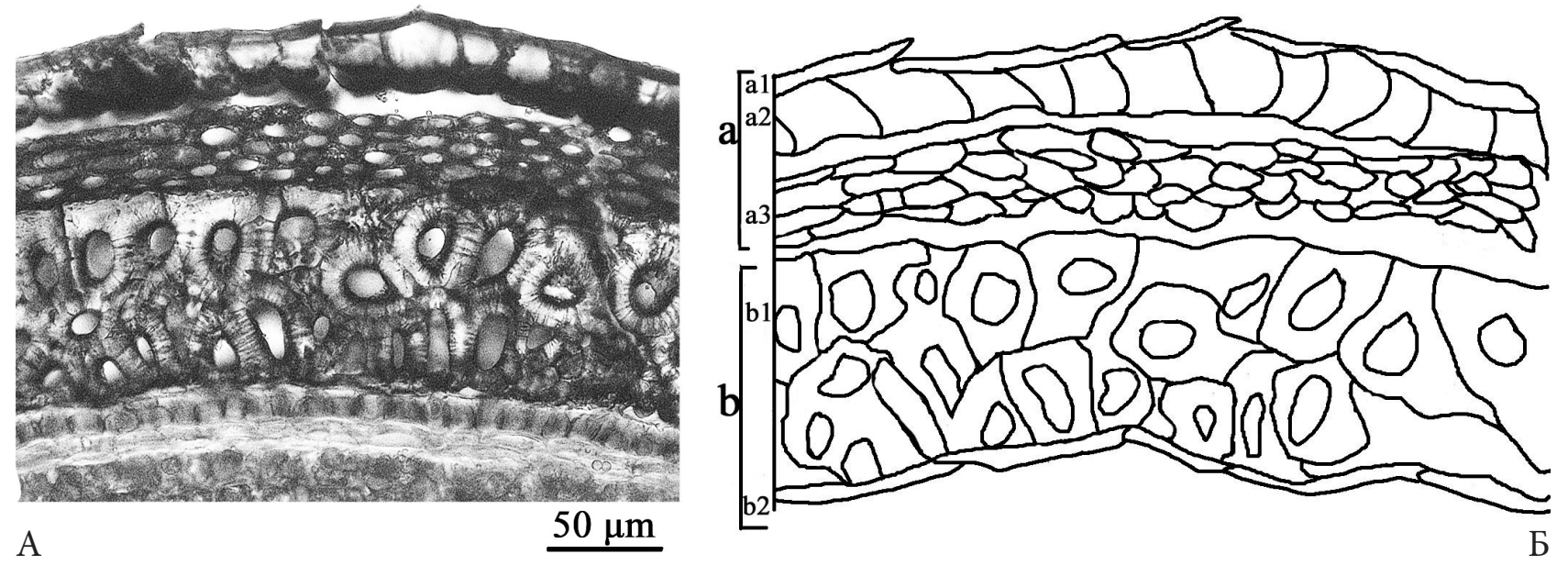

Рис. 2. Строение спермодермы Viola hirta L. A - микрофотография, Б - схема строения спермодермы, а - теста (a1, a2 - экзотеста, a3 - мезотеста); b - тегмен (b1 - экзотегмен, склеренхимные клетки, b2 - эндотегмен).

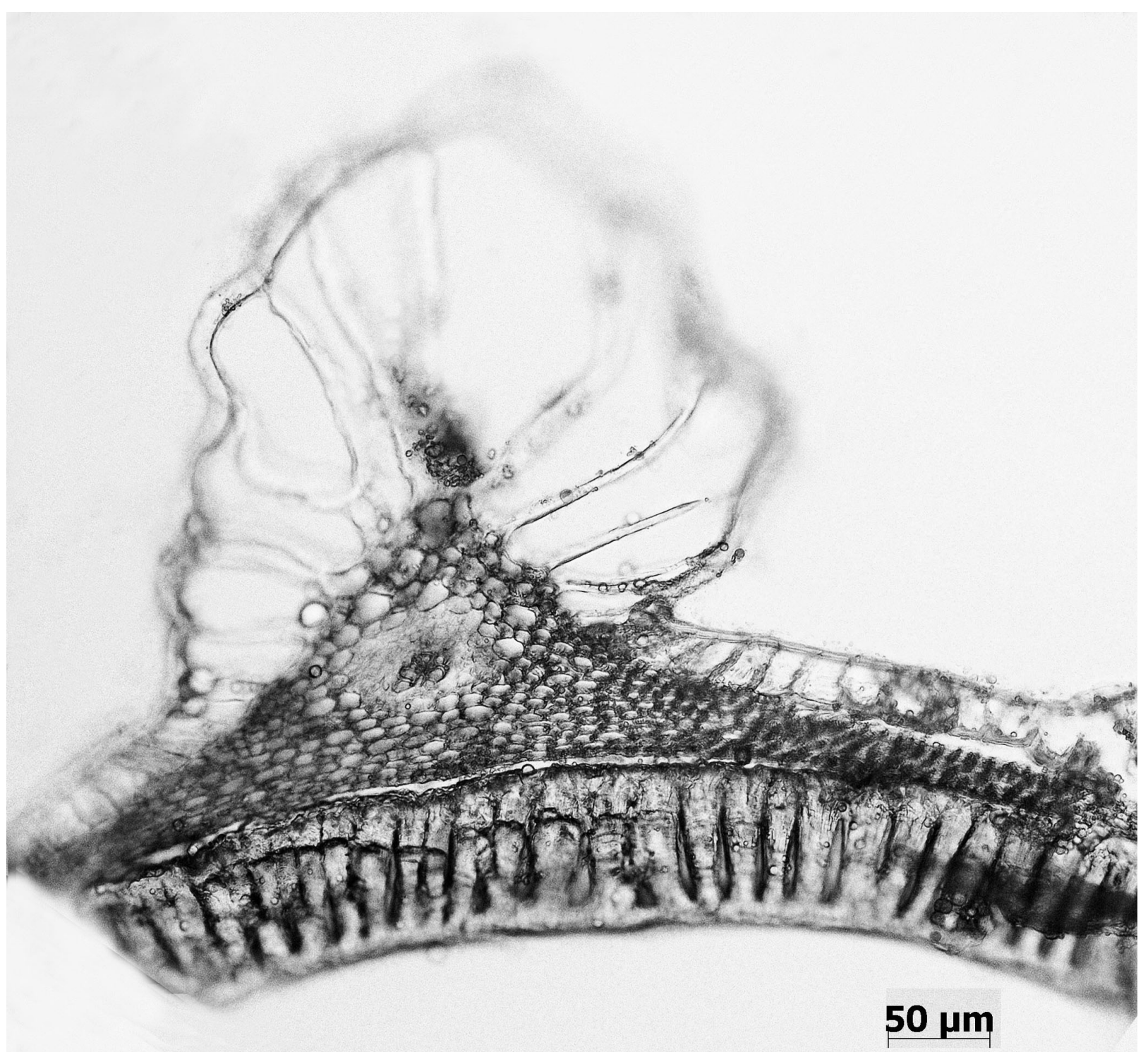

Рис. 3 Ариллоид Viola hirta L. 
Исследования ультраскульптуры спермодермы у сибирских видов рода Viola выявили кристаллоносный слой (Елисафенко, 2018a). Предварительные исследования анатомии семян других сибирских видов показали, что чаще всего этот слой не видно. У V. hirta выявляется на продольных срезах кристаллоносный слой клеток, который не различим на поперечном срезе (рис. 4). Н. Ф. Вылцан (1990) для видов секций Rosulantes и Arosulatae указывает, что эти клетки можно наблюдать только при продольном срезе. Таким образом, эндотеста у видов рода Viola представлена 1 рядом многогранных клеток (тетро-, пентогональные).

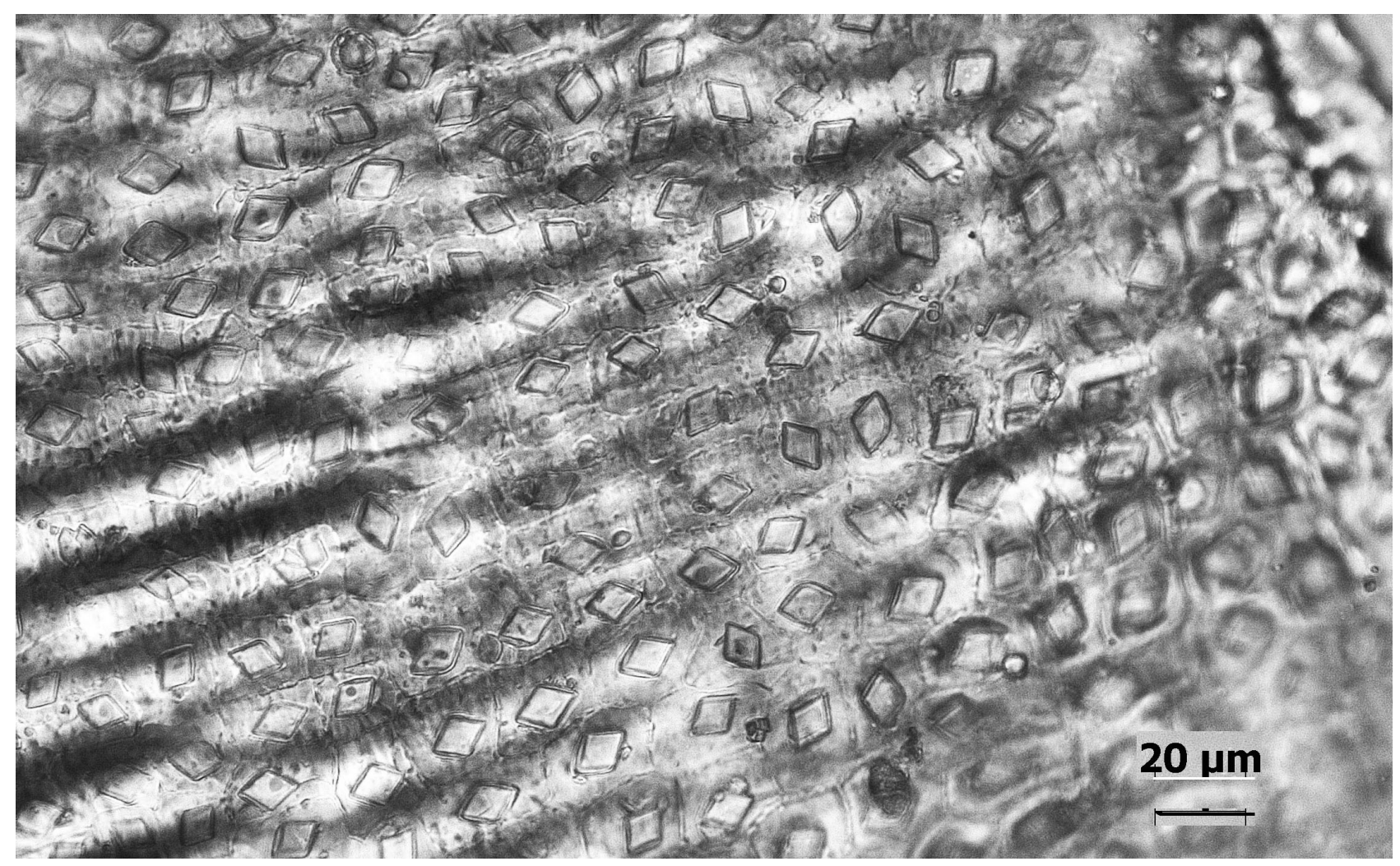

Рис. 4. Эндотеста Viola hirta L. Кристаллоносные клетки.

Большую часть в спермодерме (66 \%) занимает тегмен $(86,12 \pm 2,48 \mu \mathrm{m}, \mathrm{V}=18,64$ \%). Экзотегмен - самый крупный слой тегмена состоит из склеренхимных клеток. На поперечном разрезе они имеют вид столбчатых клеток, на продольном срезе - длинные и изогнутые (рис. 5) На поперечном разрезе часто можно видеть срезы нескольких клеток одновременно, что создает впечатление двурядности или беспорядочного расположения клеток. Под экзотегменом находится слой близко прилегающих удлиненных сдавленных и часто дезинтегрированных клеток, это остатки мезотегмена.

Семена V. selkirkii мелкие орехового цвета. В условиях интродукции масса 1000 семян достигает 0,65 г. Семена с крупным эндоспермом и зародышем. Спермодерма многослойная выделяются теста и тегмен (рис. 6). Теста составляет $8,77 \pm 0,44 \mu \mathrm{m}(\mathrm{V}=22,66 \%)$. Верхний слой экзотесты представлен кутикулой. Большая часть тесты представлена мезотестой - плотно прилегающими округлыми клетками в 2-3 ряда, в них содержатся пигменты. Мезотеста составляет больше половины тесты $-6,86 \pm 0,89$ $\mu \mathrm{m}(\mathrm{V}=56,50 \%)$. Кристаллоносный слой клеток не различается, но он имеется (выявлен при исследовании ультраскульптуры спермодермы). Тегмен занимает $73 \%$ спермодермы $(51,93 \pm 2,54 \mu \mathrm{m}, \mathrm{V}=24,42$ \%). Экзотегмен на поперечном разрезе имеет вид столбчатых клеток. Мезотегмен представлен одним рядом тонких удлиненных клеток.

В результате установлено, что у крупных семян $V$. hirta спермодерма в 2 раза толще, чем у мелких семян $V$. selkirkii, а теста в 4,5 раза тоньше. Это, возможно, объясняет отсутствие покоя у семян $V$. 

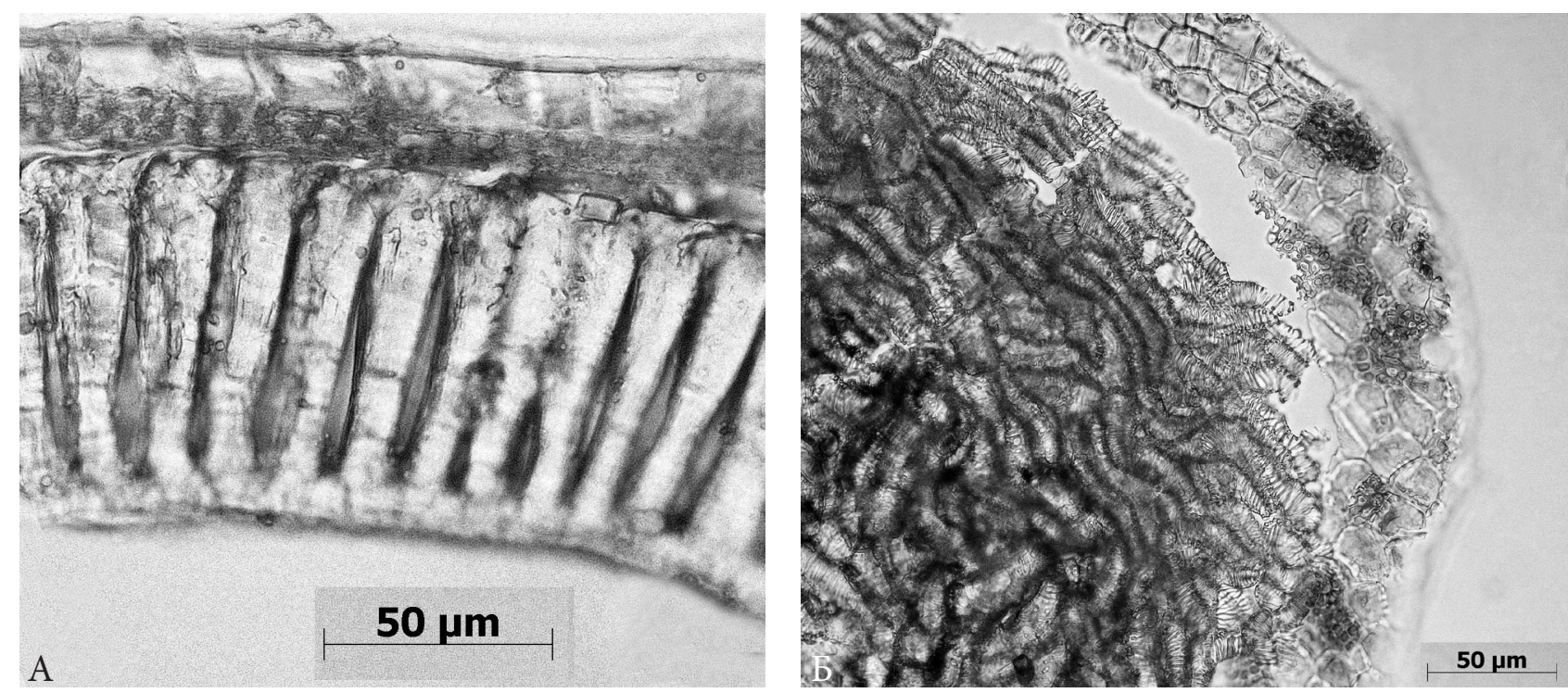

Рис. 5. Экзотегмен Viola hirta L. А - поперечный срез; Б - продольный срез.
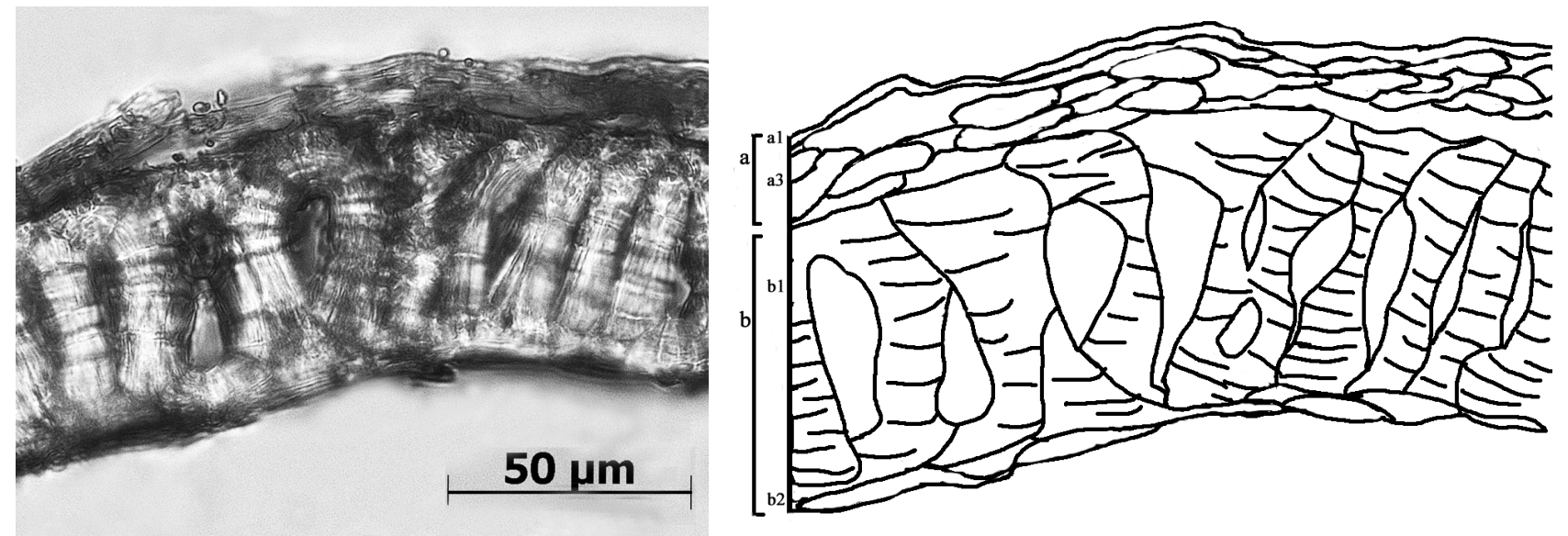

Рис. 6. Строение спермодермы Viola selkirkii Pursh. А - микрофотография, Б - схема строения спермодермы, а теста (a1 - экзотеста, a3 - мезотеста); b - тегмен (b1 - экзотегмен, склеренхимные клетки, b2 - эндотегмен).

selkirkii. Такая тонкая спермодерма может определяться условиями произрастания этого вида и экологической группой. Тегмен у обоих видов составляет значительную часть в спермодерме и является основным защитным слоем семенной кожуры. Причем, несмотря на значительную разницу в толщине спермодермы, размеры тегмена у изученных видов отличаются в меньшей степени (в 1,5 раза).

На основании проведенного исследования и литературных данных мы предлагаем предварительную обобщенную схему спермодермы для видов рода Viola (рис. 7). Спермодерма многослойная, в ее формировании принимают участие наружный и внутренний интегументы семязачатка. Производными наружного интегумента являются три слоя тесты. Клетки экзотесты в дальнейшем участвуют в формировании ариллоида. Мезотеста состоит из пигментированных клеток, которые определяют цвет семенной кожуры. Эндотеста представлена 1 рядом кристаллоносных клеток. Производными внутреннего интегумента является тегмен. Экзотегмен состоит из крупных склеренхимных клеток, которые определяют прочность семенной кожуры. В литературе отмечается, что однорядность и двурядность экзотегмена имеет систематическое значение на уровне секций (Вылцан 1990, 1992; Никитин, 2001). Мезо- и экзотегмен часто в зрелых семенах дезинтегрирован, и они не выделяются (Вылцан, 1990, 1992, 1998; Никитин, 2001). В незрелых семенах Viola odorata можно наблюдать эти два слоя (Плиско, 1992). 

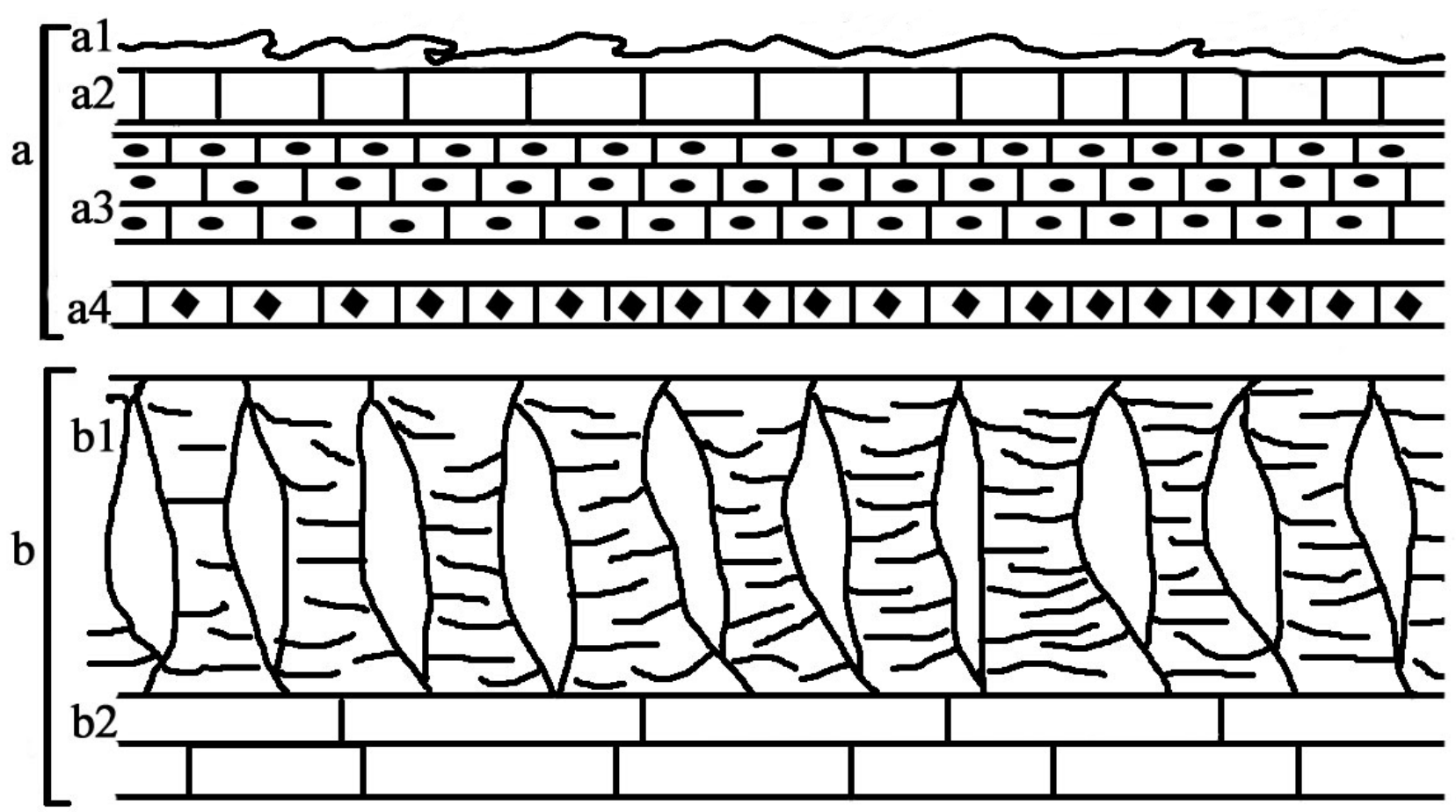

Рис. 7. Обобщенная предварительная схема строения спермодермы видов рода Viola L.

a - теста: a1, a2 - экзотеста с кутикулой, а3 - мезотеста (пигментированные клетки), а4 - эндотеста (кристаллоносные клетки); b - тегмен: b1 - экзотегмен (склеренхимные клетки), b2 - эндотегмен.

Предложенную схему предполагается использовать в дальнейшем анализе модификации спермодермы у других видов рода Viola. Следует учитывать толщину спермодермы, тесты, слоя пигментированных клеток, число рядов и форму клеток, толщину тегмена, выраженность мезо- и эндотегмена, и форму клеток составляющую эти слои. Кроме этого аллометрические признаки: отношение толщины мезотесты к тесте, экзотегмена к спермодерме и экзотегмена к тесте.

Таким образом, зрелые семена $V$. hirta и $V$. selkirkii тестально-тегмальные с наибольшим развитием тегмена, который представлен одним рядом крупных склеренхимных клеток экзотегмена. Экзотегмен в зрелых семенах дезинтегрирован, мезотегмен частично дезинтегрирован у V. hirta и присутствует у $V$. selkirkii. Теста состоит из 3 слоев: экзотесты (кутикула и слой клеток участвующий в формировании ариллоида), мезотесты - 3-4 ряда пигментированных клеток ( $V$. hirta) и 2-3 ряда (V. selkirkii ) и эндотесты - 1 ряд кристаллоносных клеток.

Благодарности. В статье использовались материалы биоресурсной коллекции ЦСБС СО РАН, УНУ «Коллекции живых растений в открытом и закрытом грунте», USU-440534. Исследования выполнены при финансовой поддержке базового проекта: № гос. регистрации: АААА-А17-117012610051-5.

\section{ЛИТЕРАТУРА}

Bылцан H. Ф. Анатомическое строение семенной кожуры для целей систематики сибирских видов рода Viola L. // Сист. Заметки по материалам Гербария А. Н. Крылова при Томск. гос. ун-те и Томск. отд. ВБО, 1990. - С. $8-10$.

Bылцан H. Ф. Анатомические признаки семенной кожуры в систематики видов рода Viola L. // Сист. заметки по материалам Гербария А. Н. Крылова при Томск. гос. ун-те и Томск. отд. ВБО, 1992. - С. 10-13.

Вылцан Н. Ф. Особенности строения семенной кожуры сибирских фиалок секции Plagiostigma Gord (Violaceae) в связи с их систематикой //Сист. Заметки по материалам Гербария А. Н. Крылова при Томск. гос. ун-те и Томск. отд. ВБО, 1998. - С. 18-20. 
Елисафенко T. В. Некоторые морфологические особенности строения семян видов рода Viola L. // Проблемы ботаники Южной Сибири и Монголии: Сб. науч. ст. по материалам XVII Междун. науч.-практ. конф. (24-27 мая 2018 г., г. Барнаул). - Барнаул: Из-во АГУ, 2018а. - С. 190-194.

Елисафенко T. В. Род Viola L. в Сибири (биология, сохранение видового разнообразия). - Новосибирск, 2018б. -683 c.

Никитин В. В. Критические заметки по систематике рода Viola L. (Violaceae) // Новости сист. высш. раст., 2001. - T. 33. - C. 172-190 c.

Паушева 3. П. Практикум по цитологии растений. - М., 1988. - 271 с.

Плиско М. А.Семейство Violaceae //Сравнительная анатомия семян. - С.-П.: Наука, 1992. - С. $99-109$.

Gil-ad N. L. The micromorphologies of seed coats and petal trichomes of the taxa of Viola subsect. Boreali-Americanae (Violaceae) and their utility in discerning orthospecies from hybrids // Brittonia, 1998. - Vol. 50, № 1. - P. 91-121. 